\title{
Flash glucose monitoring system: impact on glycemic control and body mass index in type 1 diabetes mellitus
}

${ }^{1}$ Departamento de Endocrinologia do Hospital de Braga, Braga, Portugal
Correspondence to: Juliana Marques Sá Sete Fontes, São Victor 4710-243 - Braga, Portugal juliana.pm.sa@gmail.com

Received on Nov/14/2020 Accepted on July/12/2021

\author{
Juliana Marques Sá \\ https://orcid.org/0000-0003-2193-1739 \\ Sara Campos Lopes ${ }^{1}$ \\ https://orcid.org/0000-0002-3888-5938 \\ Mariana Barbosa ${ }^{1}$ \\ https://orcid.org/0000-0002-8604-6477 \\ Inês Ferreira Barros ${ }^{1}$ \\ https://orcid.org/0000-0001-8929-5762 \\ Maria Joana Santos ${ }^{1}$ \\ https://orcid.org/0000-0002-0023-0725
}

\begin{abstract}
Objective: Flash glucose monitoring (FGM) is increasingly used in type 1 diabetes mellitus (T1D) management. This study aimed to assess glycated hemoglobin (HbA1c) and body mass index (BMI) in the first year of FGM use in patients withT1D and to identify predictive factors of benefit associated with its use. Subjects and methods: Retrospective study ofT1D patients, using FGM for $\geq 6$ months and under intensive insulin therapy with multiple daily injections. Results: In 179 patients with a median (Md) age of 43.0 years (P25 31.0; P75 52.0) and disease duration of 18.0 years (P25 10.0; P75 28.0), initial $\mathrm{HbA}_{1} \mathrm{c}$ was 7.9\% (P25 7.2; P75 8.8) and initial BMI was $24.0 \mathrm{~kg} / \mathrm{m}^{2}$ (P25 21.9; P75 26.2). With FGM, HbA1c improved significantly to 7.6\% (P25 7.0; P75 8.3) at 6 months and 7.7\% (P25 6.95; P75 8.5) at 12 months $(\mathrm{p}<0.05)$, with more patients with $\mathrm{HbA}_{1} \mathrm{c}<7 \%(16.1 \%$ vs $22.5 \%)$ and fewer patients with $\mathrm{HbA}_{1} \mathrm{c} \geq 8 \%$ (49.1\% vs 35.8\%) ( $\mathrm{p}<0.05$ ). Initial $\mathrm{HbA}_{1} \mathrm{c} 8.0-8.9 \%$ (HR 1.886; 95\% $\mathrm{Cl} 1.321-2.450$ ) and $\geq 9.0 \%$ (HR 3.108, 95\% $\mathrm{Cl} 2.454-3.761$ ) predicted greater $\mathrm{HbA}_{1} \mathrm{c}$ reduction. BMI increased significantly, especially between 6 and 12 months (BMI Md 23.8 [P25 21.9; P75 26.2] kg/m² and 24.0 [P25 22.0; P75 26.2] kg/m², respectively) ( $p<0.05$ ). Overweight (HR 4.319, 95\% Cl 3.185-5.453) and obesity (HR $8.112,95 \% \mathrm{Cl} 3.919-12.306)$ predicted greater weight gain. Conclusion: FGM use was associated with significant improvement in $\mathrm{HbA}_{1} \mathrm{c}$, mainly in patients with worse previous glycemic control. It was also associated with increased BMI, especially if baseline $\mathrm{BMI} \geq 25 \mathrm{~kg} / \mathrm{m}^{2}$, so weight control strategies should be emphasized. Arch Endocrinol Metab. 2021;65(5):640-7
\end{abstract}

Keywords

Diabetes; type 1 diabetes; flash glucose monitoring; glycated hemoglobin; body mass index

\section{INTRODUCTION}

Self-monitoring of blood glucose (SMBG) has long $S_{\text {been one of the key elements of type } 1 \text { diabetes }}$ mellitus (TID) management. This method enables patients to assess their blood glucose levels at any time using finger-stick blood samples, test strips and glucose meters $(1,2)$. In recent years, however, the appearance of new technologies, such as flash glucose monitoring (FGM), which facilitate the monitoring of interstitial glucose, has changed the lives of many patients with TID $(2,3)$. Whereas SMBG provides isolated blood glucose values, FGM, through painless scanning, provides considerably more information, such as the direction and velocity of glycemic changes (i.e., trend arrows), estimated glycated hemoglobin $\left(\mathrm{HbA}_{1} \mathrm{c}\right)$, average glucose, percentage of readings above, below and within the predefined target range, number and duration of hypoglycemic events and daily profiles (2). This allows for a reduction in hypoglycemic events and glucose variability, as well as an improvement in glycemic control, quality of life and treatment satisfaction $(2,4,5)$.

The most modern FGM devices demonstrate a mean absolute relative difference in glucose values of $11.4 \%$ compared to SMBG, allowing the collected data to be used for self and hetero adjustment of insulin 
doses (6). Changes in interstitial glucose are seen with a delay of approximately 5 minutes relative to blood glucose, so there are situations in which there is a higher and lower correlation between the values provided by FGM and SMBG, namely in the first 24 hours of use, extreme values (hypoglycemia and hyperglycemia) and when rapid changes in glucose levels occur. SMBG measurements are recommended to confirm the values obtained via FGM when interstitial glucose readings change rapidly, to confirm hypoglycemia and when symptoms do not correspond to FGM values $(2,5,7)$.

Scanning the FGM device several times a day was associated with better $\mathrm{HbA}_{1} \mathrm{c}$ values, higher percentage of time in the glycemic target range, less time in nocturnal hypoglycemia and less severe hypoglycemic events $(<55$ $\mathrm{mg} / \mathrm{dL})(5,8-10)$. Moreover, recent studies have shown that FGM use is associated with a substantial reduction in $\mathrm{HbA}_{1} \mathrm{c}$, particularly in individuals with higher $\mathrm{HbA}_{1} \mathrm{c}$ values before its use $(5,11)$.

Currently, our endocrinology department follows about 600 patients diagnosed with TID. Most of our patients have access to FGM devices, which have been reimbursed by the government in Portugal since January 2018.

The main aim of this study was to assess the impact of continuous FGM device use for at least 6 months in TID patients and to identify predictive factors of benefit associated with the use of this technology.

\section{SUBJECTS AND METHODS}

\section{Study design and participants}

This observational and retrospective study's target population included patients with TID who underwent follow-up at the Endocrinology Department of Hospital de Braga, Portugal.

Study eligibility criteria were TID diagnosis, being 18 years or older, using a FGM device continuously for at least 6 months and undergoing intensive insulin therapy by multiple daily injections (MDI). Exclusion criteria included intermittent or less than 6 months of device use, being an insulin infusion pump carrier, pregnancy, initiation or suspension of hypoglycemic drugs (e.g., metformin, glucagon-like peptide-1 [GLP-1] analogs or sodium-glucose co-transporter 2 inhibitors [iSGLT-2]) and/or change in the basal insulin type during the analyzed period.
All patients were treated with a basal-bolus regimen (long-acting and rapid-acting insulin analogues), and we subdivided the patients into 2 groups: "functional insulin therapy" and "fixed doses". "Functional insulin therapy" refers to a regimen in which patients know how to count carbohydrates and use the concepts of carbohydrate-to-insulin ratio and insulin sensitivity factor, which could be different for each meal (12). The term "fixed doses" refers to treatment used for patients who did not count carbohydrates and who used a fixed table to know how much rapid-acting insulin they should take, according to glycemic level and specific meal.

The data were collected by consulting electronic clinical records. The study was performed according to a protocol properly approved by the local ethics committee (reference 226_2019).

\section{Outcomes}

Our primary outcome was the longitudinal evolution of $\mathrm{HbA}_{1} \mathrm{c}$ at 6 and 12 months after initiation of FGM use. Our secondary outcome was the longitudinal evolution of BMI, as a surrogate marker of weight. Possible predictive factors for the greatest benefit of the use of this technology, namely sex, functional insulin therapy, age, diabetes duration, initial $\mathrm{HbA}_{1} \mathrm{c}$, initial $\mathrm{BMI}$, variation of long-acting insulin dose and variation of $\mathrm{BMI}$ or $\mathrm{HbA}_{1} \mathrm{c}$, were also evaluated for each outcome.

\section{Statistical analysis}

Collected data was analyzed using IBM SPSS ${ }^{\circledR}$ version 26.0 (IBM Corp., Armonk, NY, USA) and STATA IC ${ }^{\circledR} 14$ software (StataCorp, College Station, Texas, USA).

For continuous quantitative variables, we assessed the presence of normal distribution through histogram analysis, the Shapiro-Wilk test and asymmetry and kurtosis evaluations. Because the data were distributed non-normally, we present our results using the median, $25^{\text {th }}$ and $75^{\text {th }}$ percentiles, as well as minimum and maximum values. For categorical variables, we present absolute numbers and percentages. We divided patients into subgroups according to age, disease duration and $\mathrm{HbA}_{1} \mathrm{c}$ value considering the 25th, 50th and 75th quartiles of the distribution of our sample in these variables. For BMI, we used the cutoffs recommended by the World Health Organization (13).

For comparisons between groups, we used Fisher's exact test for categorical variables and the Kruskal- 
Wallis test for continuous variables. To compare paired samples at various follow-up times, we used the Wilcoxon test.

Models of univariate longitudinal regression adjusted for the initial value of $\mathrm{HbA}_{1} \mathrm{c}$, and $\mathrm{BMI}$ were constructed. Multivariate longitudinal regression models were also constructed to analyze possible predictors of the variation of $\mathrm{HbA}_{1} \mathrm{c}$ and $\mathrm{BMI}$ after FGM device use.

We used a 95\% confidence interval and considered a result statistically significant if $\mathrm{p}<0.05$.

\section{RESULTS}

The population's baseline characteristics are presented in Table 1 . We included 179 patients with a median (Md) age of 43.0 years and a median duration of disease of 18.0 years. Approximately $33.5 \%$ of the patients were under a functional insulin therapy regimen. The initial median $\mathrm{HbA}_{1} \mathrm{c}$ was 7.9\% (P25 7.2; P75 8.8), and $49.1 \%$ of patients presented initial $\mathrm{HbA}_{1} \mathrm{c} \geq 8 \%$. The initial median BMI was 24.0 $\mathrm{kg} / \mathrm{m}^{2}$ (P25 21.9; P75 26.2), and 39\% of patients were overweight or obese. All our patients used FGM at least for 6 months, and $74.3 \%$ of them used it for 12 months or more.

To analyze the $\mathrm{HbA}_{1} \mathrm{c}$ and weight variation, we assessed the variation of the long-acting insulin dose, since this variable affects both $\mathrm{HbA}_{1} \mathrm{c}$ and weight. The daily long-acting insulin dose $(\mathrm{U} / \mathrm{kg} /$ day) did not undergo statistically significant changes over the 12 months analyzed ( $\mathrm{p}=0.111$ from 0 to 6 months and $\mathrm{p}=0.078$ from 6 to 12 months). The doses of rapidacting insulin analogues were not analyzed statistically, as some patients were treated with functional insulin therapy, while others used insulin in fixed doses.

\section{Evolution and predictors of change in HbA1c with FGM use}

During the first year of FGM use, $\mathrm{HbA}_{1} \mathrm{c}$ decreased significantly in our population, especially in the first 6 months of use (Table 2; Figure 1). We observed a significant increase in the number of patients with $\mathrm{HbA}_{1} \mathrm{c}<7 \%(16.1 \%$ at baseline vs. $22.5 \%$ at 6 months, $\mathrm{p}<0.001)$ and a reduction in the number of patients with $\mathrm{HbA}_{1} \mathrm{c} \geq 8 \%$ (49.1\% at baseline vs. $37.1 \%$ at 6 months, $\mathrm{p}<0.001$ ). From 6 to 12 months of analysis, the trend remained, but it lacked statistical significance.
Table 1. Patient characteristics at baseline

\begin{tabular}{|c|c|}
\hline \multicolumn{2}{|l|}{ Sex } \\
\hline Male & $94(52.5 \%)$ \\
\hline Female & $85(47.5 \%)$ \\
\hline Age (years) ${ }^{a}$ & $43(31 ; 52)(18 ; 80)$ \\
\hline \multicolumn{2}{|l|}{ Age (groups) } \\
\hline$\leq 29$ & 40 (22.4\%) \\
\hline $30-39$ & $33(18.4 \%)$ \\
\hline $40-49$ & $52(29.1 \%)$ \\
\hline$\geq 50$ & $54(30.2 \%)$ \\
\hline Diabetes duration (years) ${ }^{\mathrm{a}}$ & $18(10 ; 28)(1 ; 62)$ \\
\hline \multicolumn{2}{|l|}{ Diabetes duration (groups) (years) } \\
\hline$\leq 9$ & $41(22.9 \%)$ \\
\hline $10-19$ & $55(30.7 \%)$ \\
\hline $20-29$ & 41 (22.9\%) \\
\hline$\geq 30$ & $42(23.5 \%)$ \\
\hline Treatment with functional insulin therapy & $60(33.5 \%)$ \\
\hline \multicolumn{2}{|l|}{ Long-acting insulin } \\
\hline Glargine & $153(85.5 \%)$ \\
\hline Detemir & $21(11.7 \%)$ \\
\hline $\mathrm{NPH}$ & $5(2.8 \%)$ \\
\hline Long-acting insulin daily dose (U) ${ }^{\mathrm{a}}$ & $22(16 ; 30)(6 ; 68)$ \\
\hline Long-acting insulin daily dose $(\mathrm{U} / \mathrm{kg} / \text { day) })^{a}$ & $0.32(0.26 ; 0.45)(0.11 ; 0.90)$ \\
\hline $\mathrm{HbA}_{1} \mathrm{C}(\%)^{\mathrm{a}}$ & $7.9(7.2 ; 8.8)(5.6 ; 13.8)$ \\
\hline \multicolumn{2}{|l|}{$\mathrm{HbA}_{1} \mathrm{C}$ (groups) (\%) } \\
\hline$<7.0$ & $26(16.2 \%)$ \\
\hline $7.0-7.9$ & $56(34.8 \%)$ \\
\hline $8.0-8.9$ & $42(26.1 \%)$ \\
\hline$\geq 9.0$ & $37(23.0 \%)$ \\
\hline Weight (kg) ${ }^{\mathrm{a}}$ & $67.3(59.3 ; 74.5)(48.4 ; 97.8)$ \\
\hline BMI $\left(\mathrm{kg} / \mathrm{m}^{2}\right)^{\mathrm{a}}$ & $24(21.9 ; 26.2)(17.2 ; 33.7)$ \\
\hline \multicolumn{2}{|l|}{ BMI (Groups) (kg/m²) } \\
\hline$<25.0$ & $97(61.1 \%)$ \\
\hline $25.0-29.9$ & $54(34.0 \%)$ \\
\hline$\geq 30.0$ & $8(5.0 \%)$ \\
\hline \multicolumn{2}{|l|}{ FGM usage time (months) } \\
\hline $6-11$ & 46 (25.7\%) \\
\hline $12-17$ & 62 (34.6\%) \\
\hline $18-23$ & $54(30.2 \%)$ \\
\hline$\geq 24$ & 17 (9.5\%) \\
\hline
\end{tabular}

aMedian (P25, P50) (min; max).

We constructed multiple univariate longitudinal regression models adjusted to initial $\mathrm{HbA}_{1} \mathrm{c}$ for each potential predictor of its evolution (Table 2). Gender, modality of treatment and initial BMI were not 
Table 2. Longitudinal evolution of $\mathrm{HbA}_{1} \mathrm{c}$ by subgroup (univariate longitudinal regression adjusted to the initial $\mathrm{HbA1c}$ value)

\begin{tabular}{|c|c|c|c|c|c|c|}
\hline $\mathrm{HbA}_{1} \mathrm{c}$ & Initial & 6 months & 12 months & HR & Cl & $\mathbf{p}$ \\
\hline Global & $\begin{array}{c}7,9(7,2 ; 8,8) \\
(5,6 ; 13,8)\end{array}$ & $\begin{array}{c}7,6(7,0 ; 8,3) \\
(5,7 ; 16,4)\end{array}$ & $\begin{array}{c}7,7(6,95 ; 8,5) \\
(5,9 ; 13,7)\end{array}$ & -0.127 & $-0.237 ;-0.016$ & $<0.05$ \\
\hline \multicolumn{7}{|l|}{ Sex } \\
\hline Male & $7,7(7,1 ; 8,6)^{*}$ & $7,6(6,9 ; 8,2)$ & $7,5(6,9 ; 8,4)$ & 0.0136 & $-0.201 ; 0.228$ & 0.901 \\
\hline Female & $8,3(7,4 ; 9,3)^{*}$ & $7,6(7,2 ; 8,6)$ & $7,8(7,2 ; 8,6)$ & & & \\
\hline \multicolumn{7}{|c|}{ Treatment with functional insulin therapy } \\
\hline No & $7,9(7,3 ; 9,3)$ & $7,6(7,1 ; 8,3)$ & $7,8(7,2 ; 8,5)$ & -0.022 & $-0.241 ; 0.197$ & 0.844 \\
\hline Yes & $7,9(7,1 ; 8,7)$ & $7,5(7,0 ; 8,1)$ & $7,6(6,8 ; 8,5)$ & & & \\
\hline \multicolumn{7}{|l|}{ Age (groups) } \\
\hline$\leq 29$ years & $8,0(7,2 ; 9,3)$ & $7,4(7,0 ; 8,5)$ & $7,6(6,8 ; 8,5)$ & -0.018 & $-0.113 ; 0.077$ & 0.710 \\
\hline $30-39$ years & $8,2(7,2 ; 9,3)$ & $7,6(7,0 ; 8,6)$ & $7,6(7,2 ; 8,5)$ & & & \\
\hline $40-49$ years & $8,0(7,4 ; 8,7)$ & $7,7(6,95 ; 8,3)$ & $7,8(6,9 ; 8,6)$ & & & \\
\hline$\geq 50$ years & $7,6(7,1 ; 8,6)$ & $7,6(7,3 ; 7,9)$ & $7,9(7,4 ; 8,4)$ & & & \\
\hline \multicolumn{7}{|c|}{ Diabetes duration (groups) } \\
\hline$\leq 9$ years & $8,0(7,3 ; 9,5)$ & $7,8(7,2 ; 8,8)$ & $7,6(7,2 ; 8,5)$ & -0.094 & $-0.187 ;-0.001$ & $p<0.05^{a}$ \\
\hline $10-19$ years & $8,0(7,5 ; 8,8)$ & 7,8 (7,3; 8,3) & $7,7(7,2 ; 8,3)$ & & & \\
\hline $20-29$ years & $8,2(7,2 ; 9,0)$ & $7,6(6,8 ; 8,2)$ & $8,2(6,8 ; 8,7)$ & & & \\
\hline$\geq 30$ years & $7,6(6,9 ; 8,2)$ & $7,5(6,8 ; 7,9)$ & $7,5(6,7 ; 7,9)$ & & & \\
\hline \multicolumn{7}{|l|}{ BMI (groups) } \\
\hline$<25.0 \mathrm{~kg} / \mathrm{m}^{2}$ & $8,1(7,5 ; 9,3)$ & $7,9(7,3 ; 8,5)^{\star}$ & $7,9(7,3 ; 8,6)^{\star *}$ & -0.014 & $-0.177 ; 0.204$ & 0.889 \\
\hline $25.0-29.9 \mathrm{~kg} / \mathrm{m}^{2}$ & $7,7(7,2 ; 8,6)$ & $7,5(6,8 ; 7,8)^{*}$ & $7,4(6,9 ; 7,9)^{\star \star}$ & & & \\
\hline$\geq 30.0 \mathrm{~kg} / \mathrm{m}^{2}$ & $8,1(7,4 ; 9,5)$ & $8,2(7,9 ; 9,7)^{\star}$ & $8,8(7,6 ; 9,0)^{\star \star}$ & & & \\
\hline \multicolumn{7}{|l|}{ Initial $\mathrm{HbA}_{1} \mathrm{C}$ (groups) } \\
\hline$<7 \%$ & $6,5(6,2 ; 6,7)^{\star}$ & $6,5(6,1 ; 7,1)^{*}$ & $6,5(6,2 ; 6,9)^{\star}$ & 1.012 & $0.889 ; 1.144$ & $<0.001^{b}$ \\
\hline $7-7.9 \%$ & $7,5(7,2 ; 7,7)^{\star}$ & $7,4(7,0 ; 7,8)^{\star}$ & $7,5(6,9 ; 7,9)^{\star}$ & & & \\
\hline $8-8,9 \%$ & $8,4(8,2 ; 8,8)^{*}$ & $8,0(7,6 ; 8,5)^{*}$ & $7,9(7,5 ; 8,6)^{\star}$ & & & \\
\hline$\geq 9 \%$ & $10,2(9,5 ; 11,1)^{\star}$ & $9,0(8,2 ; 9,7)^{\star}$ & $8,5(7,7 ; 10,6)^{*}$ & & & \\
\hline
\end{tabular}

Median (p25; p75) (min; max). ${ }^{\star} p<0.05$. ${ }^{\star \star} 0.05<p<0.1$. a: $p<0.05$ between $20-29$ years. b: $p<0.001$ between $8-8.9 \%$ and $\geq 9 \%$.

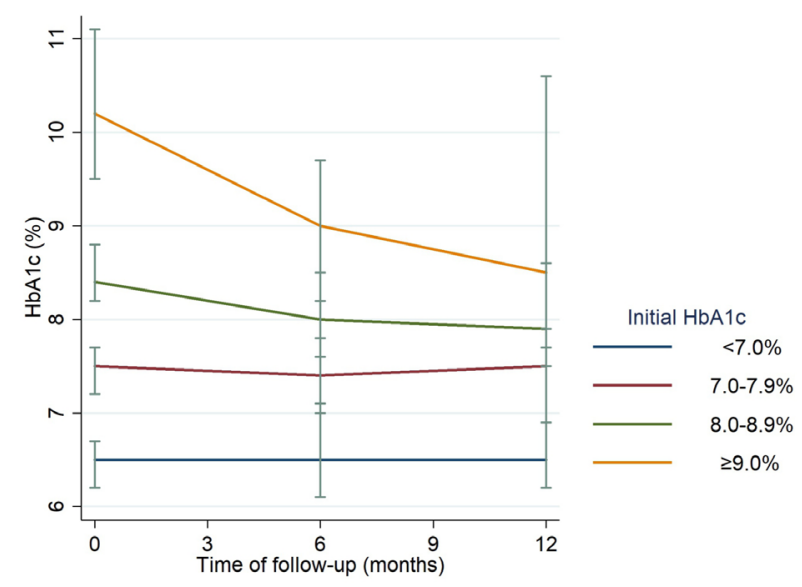

Figure 1. Longitudinal evolution of HbA1c during the 12 months of follow-up. associated with a favorable $\mathrm{HbA}_{1} \mathrm{c}$ evolution. Patients who had TID for 20-29 years had worse $\mathrm{HbA}_{1} \mathrm{c}$ evolution $(\mathrm{p}<0.05)$. Patients with the highest $\mathrm{HbA}_{1} \mathrm{c}$ at baseline $(8-8.9 \%$ and $\geq 9 \%)$ had remarkably positive $\mathrm{HbA}_{1} \mathrm{c}$ evolution $(\mathrm{p}<0.001)$ (Table 2$)$.

A multivariate longitudinal regression model for possible confounding factors for the absolute variation of $\mathrm{HbA}_{1} \mathrm{c}$ in the first 12 months of FGM use (Table 3) confirmed that patients with $\mathrm{HbA}_{1} \mathrm{c}$ 8.0$8.9 \%$, especially those with $\mathrm{HbA}_{1} \mathrm{c} \geq 9 \%$, showed the greatest improvement in glycemic control. Factors such as initial BMI of $25-29.9 \mathrm{~kg} / \mathrm{m}^{2}$ (overweight) and an increase in BMI in the first 6 months (BMI positive variation) had a negative effect on the evolution of $\mathrm{HbA}_{1} \mathrm{c}$ (Table 3). 
Table 3. Multivariate longitudinal regression model for possible confounding factors of the evolution of HbA1c during the 12 months of follow-up

\begin{tabular}{|c|c|c|c|}
\hline Factor & Coefficient & Cl & $\mathbf{p}$ \\
\hline HbA1c evolution 0-6 months & -0.475 & $-0.762 ;-0.187$ & 0.001 \\
\hline HbA1c evolution 6-12 months & -0.337 & $-0.629 ;-0.045$ & 0.024 \\
\hline \multicolumn{4}{|l|}{ Initial HbA1c (\%) ${ }^{\mathrm{a}}$} \\
\hline $7.0-7.9$ & 1.124 & $0.578 ; 1.670$ & $<0.001$ \\
\hline $8.0-8.9$ & 1.886 & $1.321 ; 2.450$ & $<0.001$ \\
\hline$\geq 9.0$ & 3.108 & $2.454 ; 3.761$ & $<0.001$ \\
\hline Sex & 0.042 & $-0.353 ; 0.437$ & 0.836 \\
\hline Treatment with functional insulin therapy & -0.162 & $-0.543 ; 0.269$ & 0.462 \\
\hline Age (years) & -0.012 & $-0.030: 0.005$ & 0.171 \\
\hline Diabetes duration (years) & -0.005 & $-0.026 ; 0.015$ & 0.612 \\
\hline \multicolumn{4}{|l|}{ Initial BMI $\left(\mathrm{kg} / \mathrm{m}^{2}\right)^{\mathrm{b}}$} \\
\hline $25-29.9$ & -0.397 & $-0.793 ;-0.001$ & 0.049 \\
\hline$\geq 30.0$ & -0.657 & $-1.850 ; 0.536$ & 0.281 \\
\hline BMl variation 0-6 months & -0.374 & $-0.598 ;-0.149$ & 0.001 \\
\hline BMl variation 6-12 months & -0.087 & $-0.350 ; 0.176$ & 0.517 \\
\hline Dose variation of long-acting insulin $0-6$ months $(\mathrm{U} / \mathrm{kg} / \mathrm{d})$ & 2.098 & $-1.102 ; 5.298$ & 0.199 \\
\hline Dose variation of long-acting insulin 6-12 months (U/kg/d) & -3.749 & $-8.312 ; 0.815$ & 0.107 \\
\hline
\end{tabular}

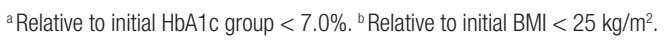

\section{Evolution and predictors of change in BMI following FGM use}

During the first 12 months of FGM use, there was a significant increase in the absolute value of BMI, especially between 6 and 12 months (Table 4). Although it lacked statistical significance, there was also a decrease in the number of patients with normal weight (61\% at baseline vs. $57.3 \%$ at 12 months) and an increase in the number of overweight or obese patients (39\% at baseline vs. $42.8 \%$ at 12 months) ( $p>0.05$ ).

We constructed multiple univariate longitudinal regression models for each potential predictor of BMI evolution, adjusting for initial BMI. The longitudinal evolution of the BMI had no relation to gender, modality of treatment, patient's age or disease duration. Patients with overweight or obesity and $\mathrm{HbA}_{1} \mathrm{c} \geq 8 \%$ at baseline showed a significant increase in BMI over the first 12 months of FGM use (Table 4).

A multivariate longitudinal regression model for possible confounding factors of BMI variation showed that patients with BMI $\geq 25 \mathrm{~kg} / \mathrm{m}^{2}$ at baseline gained more weight over the follow-up period (Table 5).

The doses of rapid-acting insulin analogues were analyzed in patients with fixed doses who gained weight and in patients who maintained or lost weight.
At baseline, rapid-acting insulin dose per $\mathrm{kg}$ was 0.22 $\mathrm{U} / \mathrm{kg}$ (P25 0.14; P75 0.40) in patients who gained weight and $0.23 \mathrm{U} / \mathrm{kg}$ (P25 0.13; P75 0.40) in those who maintained or lost weight $(\mathrm{p} \geq 0.05)$. The variation of rapid-acting insulin doses per $\mathrm{kg}$ in the first 12 months in patients who gained weight was also not statistically different from those who maintained or lost weight (Md -0.002 U/kg [P25 -0.03; P75 0.06] vs Md 0.01 $\mathrm{U} / \mathrm{kg}$ [P25 0.00; P75 0.03], respectively, $\mathrm{p} \geq 0.05$ ).

\section{DISCUSSION}

The use of continuous glucose monitoring devices is associated with improvements in glycemic control in patients with TID treated with MDI $(10,14)$. In line with previous publications $(5,11)$, our study demonstrated a statistically significant and clinically relevant improvement in $\mathrm{HbA}_{1} \mathrm{c}$ after one year of FGM use, especially in individuals with the worst initial metabolic control $\left(\mathrm{HbA}_{1} \mathrm{c} \geq 8 \%\right)$. In fact, initial $\mathrm{HbA}_{1} \mathrm{c}$ $\geq 8 \%$ was a predictor of greater benefit, regardless of patients' other characteristics, whereas overweight or weight gain in the first 6 months negatively affected the evolution of $\mathrm{HbA}_{1} \mathrm{c}$. Through FGM technology, this group of patients gained access to additional and 
Table 4. Longitudinal evolution of BMI by subgroups (univariate longitudinal regression adjusted to the initial BMI value)

\begin{tabular}{|c|c|c|c|c|c|c|}
\hline BMI & Initial & 6 months & 12 months & HR & Cl & $\mathbf{p}$ \\
\hline Global & $\begin{array}{c}24,0(21,9 ; 26,2) \\
(17,2 ; 33,7)\end{array}$ & $\begin{array}{c}23,8(21,9 ; 26,2) \\
(16,5 ; 33,3)\end{array}$ & $\begin{array}{c}24,0(22,0 ; 26,2) \\
(17,1 ; 33,1)\end{array}$ & 0.124 & $0.0245 ; 0.223$ & $<0.05$ \\
\hline \multicolumn{7}{|l|}{ Sex } \\
\hline Male & $24,0(22,1 ; 25,7)$ & $23,7(21,8 ; 26,1)$ & $24,3(22,2 ; 25,9)$ & 0.0413 & $-0.163 ; 0.246$ & 0.692 \\
\hline Female & $24,1(21,8 ; 26,7)$ & $23,8(22,1 ; 26,6)$ & $23,8(21,8 ; 26,9)$ & & & \\
\hline \multicolumn{7}{|c|}{ Treatment with functional insulin therapy } \\
\hline No & $24,1(22,4 ; 26,4)$ & $23,8(22,1 ; 26,6)$ & $24,3(22,3 ; 26,5)$ & -0.032 & $-0.252 ; 0.188$ & 0.776 \\
\hline Yes & $23,9(20,5 ; 25,9)$ & $23,8(21,1 ; 25,8)$ & $23,8(20,5 ; 25,7)$ & & & \\
\hline \multicolumn{7}{|l|}{ Age (groups) } \\
\hline$\leq 29$ years & $23,8(21,7 ; 24,5)^{\star *}$ & $23,6(21,8 ; 24,9)$ & $23,2(21,9 ; 25,4)^{\star}$ & -0.0604 & $-0.156 ; 0.035$ & 0.213 \\
\hline 30-39 years & $22,9(20,9 ; 25,4)^{\star *}$ & $23,6(21,7 ; 25,9)$ & $22,2(21,3 ; 25,0)^{\star}$ & & & \\
\hline 40-49 years & $25,2(22,6 ; 27,4)^{* *}$ & $24,4(22,3 ; 27,8)$ & $25,3(22,5 ; 28,2)^{\star}$ & & & \\
\hline$\geq 50$ years & $24,2(22,6 ; 26,2)^{\star *}$ & $23,8(22,2 ; 26,0)$ & $25,0(23,3 ; 26,3)^{\star}$ & & & \\
\hline \multicolumn{7}{|c|}{ Diabetes duration (groups) } \\
\hline$\leq 9$ years & $23,8(22,1 ; 25,4)^{*}$ & $23,4(22,1 ; 25,4)^{\star \star}$ & $23,8(22,1 ; 25,5)$ & -0.012 & $-0.1097 ; 0.086$ & 0.814 \\
\hline $10-19$ years & $23,5(21,6 ; 25,4)^{*}$ & $22,4(21,7 ; 25,4)$ ** & $22,8(21,7 ; 25,8)$ & & & \\
\hline 20-29 years & $23,9(22,4 ; 27,0)^{*}$ & $24,0(22,4 ; 26,6)$ ** & $24,9(21,5 ; 27,0)$ & & & \\
\hline$\geq 30$ years & $25,5(23,2 ; 27,5)^{\star}$ & $25,0(23,0 ; 27,2)$ ** & $25,1(23,6 ; 27,2)$ & & & \\
\hline \multicolumn{7}{|l|}{ Initial BMI (groups) } \\
\hline$<25 \mathrm{~kg} / \mathrm{m}^{2}$ & $22,6(20,9 ; 23,8)^{\star}$ & $22,6(21,2 ; 23,8)^{\star}$ & $22,5(21,1 ; 23,9)^{\star}$ & 4.484 & $3.997 ; 4.969$ & $<0.05^{a}$ \\
\hline $25-29.9 \mathrm{~kg} / \mathrm{m}^{2}$ & $26,4(25,6 ; 27,6)^{\star}$ & $27,0(25,6 ; 28,4)^{\star}$ & $26,5(25,3 ; 28,5)^{\star}$ & & & \\
\hline$\geq 30 \mathrm{~kg} / \mathrm{m}^{2}$ & $31,5(30,3 ; 32,7)^{\star}$ & $31,2(30,6 ; 31,6)^{\star}$ & $31,4(31,2 ; 31,8)^{\star}$ & & & \\
\hline \multicolumn{7}{|c|}{ Initial HbA1c (groups) } \\
\hline$<7 \%$ & $24,2(22,3 ; 25,2)$ & $23,0(22,0 ; 24,9)$ & $23,6(21,6 ; 25,1)$ & 0.122 & $0.0165 ; 0.227$ & $<0.05^{\mathrm{h}}$ \\
\hline $7-7.9 \%$ & $25,1(22,1 ; 27,4)$ & $24,0(22,0 ; 28,1)$ & $24,1(22,4 ; 27,3)$ & & & \\
\hline $8-8,9 \%$ & $24,0(21,5 ; 26,4)$ & $24,2(22,1 ; 27,8)$ & $24,6(23,0 ; 26,1)$ & & & \\
\hline$\geq 9 \%$ & $23,9(21,6 ; 25,2)$ & $23,4(21,4 ; 25,6)$ & $23,5(22,2 ; 26,2)$ & & & \\
\hline
\end{tabular}

${ }^{*} p<0.05 .{ }^{* \star} 0.05<p<0.1 .{ }^{a}$ Group $25-29.9 \mathrm{~kg} / \mathrm{m}^{2}$ and $\geq 30 \mathrm{~kg} / \mathrm{m}^{2} .{ }^{\text {b }}$ Group $8-8.9 \%$ and $\geq 9 \%$.

useful glucose data with a more convenient and painless method compared to SMBG, possibly giving them more motivation to increase the number of glucose assessments and more confidence to auto-adjust shortacting insulin doses. A possible increase in short-acting insulin doses could explain the $\mathrm{HbA}_{1} \mathrm{c}$ improvement seen over the 12 months of follow-up because all types of insulin are associated with weight gain $(15,16)$. These adjustments may have been made by the patients or by their physicians, who also had access to more information with FGM than with SMBG. Because the short-acting insulin doses were not evaluated in all patients (it was not possible to know the exact dose of rapid-acting insulin in patients on functional insulin therapy), we did not analyze that factor, so this is merely a hypothesis.
In fact, previous data demonstrated that FGM use resulted in changes in the timing of bolus administration of rapid-acting insulin, which was associated with better $\mathrm{HbA}_{1} \mathrm{c}$ values $(17,18)$. The fact that our patients were using this technology for the first time, with access to new information such as trend arrows and a graph with glycemic values throughout the day, might also explain the $\mathrm{HbA}_{1} \mathrm{c}$ improvement, especially in the first 6 months, when the device was completely novel, and more readings were probably taken per day. Obese patients consistently presented worse $\mathrm{HbA}_{1} \mathrm{c}$, which is likely associated with greater food intake, a more sedentary lifestyle and greater insulin resistance.

Regarding weight, there was an increase in BMI over the follow-up time, especially in months 6-12. The only predictive factor for weight gain after starting 
Table 5. Multivariate longitudinal regression model for possible confounding factors of the evolution of BMl during the 12 months of follow-up

\begin{tabular}{|c|c|c|c|}
\hline Factor & Coefficient & Cl & $\mathbf{p}$ \\
\hline BMI evolution 0-6 months & 0.257 & $0.025 ; 0.489$ & 0.030 \\
\hline BMI evolution 6-12 months & 0.373 & $0.141 ; 0.605$ & 0.002 \\
\hline \multicolumn{4}{|l|}{ Initial HbA1c (\%) } \\
\hline $7.0-7.9$ & 1.053 & $-0.603 ; 2.709$ & 0.213 \\
\hline $8.0-8.9$ & 0.986 & $-0.644 ; 2.616$ & 0.236 \\
\hline$\geq 9.0$ & 0.988 & $-1.048 ; 3.024$ & 0.342 \\
\hline Sex & 0.181 & $-0.987 ; 1.350$ & 0.761 \\
\hline Treatment with functional insulin therapy & -0.905 & $-2.206 ; 0.397$ & 0.173 \\
\hline Age (years) & -0.013 & $-0.062 ; 0.036$ & 0.598 \\
\hline Diabetes duration (years) & -0.008 & $-0.064 ; 0.049$ & 0.791 \\
\hline \multicolumn{4}{|l|}{ Initial BMI $\left(\mathrm{kg} / \mathrm{m}^{2}\right)^{\mathrm{b}}$} \\
\hline $25-29.9$ & 4.319 & $3.185 ; 5.453$ & 0.000 \\
\hline$\geq 30.0$ & 8.112 & $3.919 ; 12.306$ & 0.000 \\
\hline HbA1c variation 0-6 months & -0.365 & $-0.861 ; 0.131$ & 0.149 \\
\hline HbA1c variation 6-12 months & 0.188 & $-0.483 ; 0.859$ & 0.583 \\
\hline Dose variation of long-acting insulin 0-6 months (U/kg/d) & 2.578 & $-5.764 ; 10.920$ & 0.545 \\
\hline Dose variation of long-acting insulin 6-12 months (U/kg/d) & 11.173 & $-2.964 ; 25.310$ & 0.121 \\
\hline
\end{tabular}

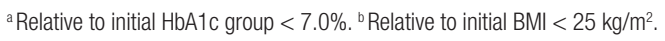

FGM was $\mathrm{BMI} \geq 25 \mathrm{~kg} / \mathrm{m}^{2}$ at baseline. Although, to our knowledge, no studies have specifically evaluated the longitudinal evolution of weight after the start of FGM, a publication aimed at evaluating the impact of FGM in people with TID in real-life conditions also found a slight increase in BMI at 6 months of follow-up (5). This weight increase was not caused by an increase in rapid-acting insulin doses, at least in patients on fixed-dose regimens, but it could be associated with the fear of hypoglycemia, which would justify greater food intake and less physical activity (16). Patients with poor glycemic control $\left(\mathrm{HbA}_{1} \mathrm{c} \geq 8 \%\right.$ ) and overweight or obese patients experienced statistically significant weight increases throughout the period analyzed.

The strengths of this study included its considerable sample size, long follow-up time and the analysis of longitudinal variation of BMI beyond the evolution of $\mathrm{HbA}_{1} \mathrm{c}$, which had not been studied so carefully before. However, there are also some limitations, such as the absence of a control group, no evaluation of rapid-acting insulin analogue doses in all patients, the study's retrospective design and the impossibility of guaranteeing that $\mathrm{HbAlc}$ and weight evaluations were performed using the same method and equipment. Furthermore, we have no information regarding lifestyle changes (e.g., diet, exercise) that may have contributed to the findings of our study. The fact that it was a retrospective study also limited the collection of information regarding the glycemic variability, time in range and number of hypoglycemic events. Although we cannot know exactly, most patients used the FGM at least 5 times daily (before breakfast, lunch, afternoon snack, dinner and bedtime) but we have no data that allow us to establish relationships between the number of scans and the results obtained in our work. It would also be interesting to analyze the educational status of our sample in a future study and check if there are differences in glycemic control according to an academic degree.

In summary, in our study of the first year of FGM use, we found a significant improvement in $\mathrm{HbAlc}$ that was consistent over the 12 -month period but more evident in the first 6 months. Patients with previous worse glycemic control experienced major improvements, whereas patients with initial overweight and those who increased their weight during the first 6 months experienced fewer benefits with this technology. FGM use was also associated with weight gain, especially in patients who were overweight or obese at baseline. Therefore, when starting FGM, weight control strategies such as a physical exercise plan and dietary changes should be considered in this specific group of individuals. 
Individual contributions: J. Marques-Sá and M. J. Santos contributed to study conception and design, analysis and interpretation of data. J. Marques-Sá, S. Campos-Lopes, M. Barbosa and I. Ferreira Barros contributed to data colletion. J. Marques-Sá drafted the article. All authors reviewed critically the article and approved the final version.

Disclosure: no potential conflict of interest relevant to this article was reported.

\section{REFERENCES}

1. Kasper D, Fauci A, Hauser S, Longo D, Jameson J, Loscalzo J. Harrison's principles of internal medicine. New York: McGrawHill; 2018.

2. Chico A, Aguilera E, Ampudia-Blasco FJ, Bellido V, CardonaHernandez R, Escalada FJ, et al. Clinical Approach to Flash Glucose Monitoring: An Expert Recommendation. J Diabetes Sci Technol. 2020;14(1):155-64.

3. McGill JB, Ahmann A. Continuous Glucose Monitoring with Multiple Daily Insulin Treatment: Outcome Studies. Diabetes TechnolTher. 2017;19(S3):S3-12.

4. Bianchi C, Aragona M, Rodia C, Baronti W, de Gennaro G, Bertolotto A, et al. Freestyle Libre trend arrows for the management of adults with insulin-treated diabetes: A practical approach. J Diabetes Complications. 2019;33(1):6-12.

5. Paris I, Henry C, Pirard F, Gérard AC, Colin IM. The new FreeStyle libre flash glucose monitoring system improves the glycaemic control in a cohort of people with type 1 diabetes followed in real-life conditions over a period of one year. Endocrinol Diabetes Metab. 2018;1(3):e00023.

6. Bailey T, Bode BW, Christiansen MP, Klaff LJ, Alva S. The Performance and Usability of a Factory-Calibrated Flash Glucose Monitoring System. Diabetes TechnolTher. 2015;17(11):787-94.

7. Rebrin K, Sheppard NF Jr, Steil GM. Use of subcutaneous interstitial fluid glucose to estimate blood glucose: revisiting delay and sensor offset. J Diabetes SciTechnol. 2010;4(5):1087-98.
8. Dunn TC, Xu Y, Hayter G, Ajjan RA. Real-world flash glucose monitoring patterns and associations between self-monitoring frequency and glycaemic measures: A European analysis of over 60 million glucose tests. Diabetes Res Clin Pract. 2018;137:37-46.

9. Bolinder J, Antuna R, Geelhoed-Duijvestijn P, Kroger J, Weitgasser R. Novel glucose-sensing technology and hypoglycaemia in type 1 diabetes: a multicentre, non-masked, randomised controlled trial. Lancet. 2016;388(10057):2254-63.

10. Beck RW, RiddlesworthT, Ruedy K, Ahmann A, Bergenstal R, Haller $\mathrm{S}$, et al. Effect of Continuous Glucose Monitoring on Glycemic Control in Adults with Type 1 Diabetes Using Insulin Injections:The DIAMOND Randomized ClinicalTrial. JAMA. 2017;317(4):371-8.

11. Tyndall V, Stimson RH, Zammitt NN, Ritchie SA, McKnight JA, Dover AR, et al. Marked improvement in HbA1c following commencement of flash glucose monitoring in people with type 1 diabetes. Diabetologia. 2019;62(8):1349-56.

12. Sachon C. L'insulinothérapie fonctionnelle [Functional insulin therapy]. Rev Prat. 2003;53(11):1169-74.

13. Physical status: the use and interpretation of anthropometry. Report of a WHO Expert Committee. World Health OrganTech Rep Ser. 1995;854:1-452.

14. Lind M, Polonsky W, Hirsch IB, Heise T, Bolinder J, Dahlqvist S, et al. Continuous Glucose Monitoring vs Conventional Therapy for Glycemic Control in Adults with Type 1 Diabetes Treated with Multiple Daily Insulin Injections: The GOLD Randomized Clinical Trial. JAMA. 2017;317(4):379-87.

15. Mathieu C, Gillard P, Benhalima K. Insulin analogues in type 1 diabetes mellitus: getting better all the time. Nat Rev Endocrinol. 2017;13(7):385-99.

16. Driscoll KA, Corbin KD, Maahs DM, Pratley R, Bishop FK, Kahkoska A, et al. Biopsychosocial Aspects ofWeight Management in Type 1 Diabetes: a Review and Next Steps. Curr Diab Rep. 2017;17(8):58.

17. Dover AR, Stimson RH, Zammitt NN, Gibb FW. Flash Glucose Monitoring Improves Outcomes in a Type 1 Diabetes Clinic. J Diabetes SciTechnol. 2017;11(2):442-3.

18. Slattery D, Amiel SA, Choudhary P. Optimal prandial timing of bolus insulin in diabetes management: a review. Diabet Med. 2018;35(3):306-16. 